Check for updates

Cite this: J. Mater. Chem. B, 2020, 8, 1017

Received 3rd November 2019 Accepted 30th December 2019

DOI: $10.1039 / c 9 t b 02453 k$

rsc.li/materials-b

\section{A ratiometric fluorescent probe for detecting the endogenous biological signaling molecule superoxide anion and bioimaging during tumor treatment $\uparrow$}

\author{
Yue Wang, ${ }^{\mathrm{ab}}$ Xiaoyan Wang, ${ }^{\mathrm{ac}} \mathrm{Li}_{\text {Zhang, }}{ }^{\mathrm{ab}}$ Yan Huang, ${ }^{\mathrm{ac}}$ Liyan $\mathrm{Bi}^{\mathrm{C}}{ }^{\mathrm{C}}$ Changjun $\mathrm{Lv}^{\mathrm{c}}$ \\ and Lingxin Chen (D)*acde
}

\begin{abstract}
Tumor resistance and drug-induced nephrotoxicity pose great challenges to the clinical treatment of tumors, and they also limit the clinical application of oncology drugs. Finding an effective adjuvant, which can sensitize tumor treatment, is an effective method for tumor treatment. Here, we developed a ratiometric fluorescent probe, TP-Tfs, for superoxide anion $\left(\mathrm{O}_{2}{ }^{-}-\right)$detection in living cells and in vivo during the process of tumor treatment for the first time. TP-Tfs with simple synthesis steps and high yields can detect $\mathrm{O}_{2}{ }^{\bullet-}$ sensitively and selectively, and the detection limit was determined to be $37 \mathrm{nM}$. Using TP-Tfs, we found that cis-diaminodichloroplatinum(II) (DDP) was effective in treating tumors by inducing $\mathrm{O}_{2}^{\bullet-}$ burst. Curcumin (cum) can sensitize tumor treatment effectively by inducing more severe $\mathrm{O}_{2}{ }^{\bullet-}$ burst. These results indicated that the probe TP-Tfs was a promising candidate for drug screening and tumor treatment evaluation.
\end{abstract}

\section{Introduction}

As a physiological by-product of normal aerobic metabolism, reactive oxygen species (ROS) play important roles in the redox system, cell growth and proliferation. ${ }^{1,2}$ The superoxide anion $\left(\mathrm{O}_{2}{ }^{--}\right)$is the primary ROS and it is mainly obtained from the mitochondrial electron transport chain and other enzyme systems, for example, xanthine oxidase, cytochrome $\mathrm{P} 450$ and nicotinamide adenine dinucleotide phosphate (NADPH) oxidases. ${ }^{3-5}$ Thus, direct or indirect damage to mitochondria facilitates electron leakage and mitochondrial $\mathrm{O}_{2}{ }^{--}$production. ${ }^{6} \mathrm{O}_{2}{ }^{--}$is the main source of other ROS, and it can be converted to other ROS and reactive nitrogen species (RNS), such as the hydroxyl $\left(\bullet^{\circ} \mathrm{OH}\right)$ radical, hydrogen peroxide $\left(\mathrm{H}_{2} \mathrm{O}_{2}\right)$ and peroxynitrite $\left(\mathrm{ONOO}^{-}\right)$, by using enzyme or non-enzymatic pathways. ${ }^{2,6}$ Therefore, the concentration of $\mathrm{O}_{2}{ }^{--}$can reflect the degree of overall oxidative stress in organisms. Once $\mathrm{O}_{2}{ }^{\bullet-}$ is increased abnormally in living cells, one or more redox regulatory mechanisms will be activated to

\footnotetext{
${ }^{a}$ CAS Key Laboratory of Coastal Environmental Processes and Ecological Remediation, Yantai Institute of Coastal Zone Research, Chinese Academy of Sciences, Yantai 264003, China. E-mail: lxchen@yic.ac.cn

${ }^{b}$ University of Chinese Academy of Sciences, Beijing 100049, China

${ }^{c}$ School of Pharmacy, Binzhou Medical University, Yantai 264003, China

${ }^{d}$ Center for Ocean Mega-Science, Chinese Academy of Sciences,

Qingdao 266071, China

${ }^{e}$ Department of Chemistry and Chemical Engineering, Qufu Normal University, Qufu 273165, China

$\dagger$ Electronic supplementary information (ESI) available. See DOI: 10.1039/c9tb02453k
}

prevent oxidative stress. A variety of physiological defense systems are dedicated to protecting normal cells from potential oxidative stress damage, such as the superoxide dismutase (SOD) family and the glutathione peroxidase family. ${ }^{2,7}$ SOD can reduce $\mathrm{O}_{2}{ }^{\cdot-}$ to $\mathrm{H}_{2} \mathrm{O}_{2}$ that is then detoxified by the glutathione peroxidase family through glutathione (GSH), thereby preventing the formation of highly aggressive compounds such as ${ }^{\bullet} \mathrm{OH}$ and $\mathrm{ONOO}^{-} .^{-}$The produced $\mathrm{O}_{2}{ }^{--}$during physiological processes can activate the necessary signaling pathways for cell growth and proliferation, meanwhile $\mathrm{O}_{2}{ }^{\bullet-}$ overproduction causes the cells to over-oxidize, and further leads to oxidative stress, metabolic disorders and cell organelle damage. The accumulated $\mathrm{O}_{2}{ }^{--}$can further cause intracellular DNA damage, trigger inflammation and increase the occurrence and development of cancer. ${ }^{8}$ Therefore, real-time monitoring of fluctuations in $\mathrm{O}_{2}{ }^{--}$concentration can provide profound insights into the regulation of $\mathrm{O}_{2}{ }^{--}$-related physiological and pathological processes.

Tumor treatment has remained a huge challenge for humans up to now. Tumor resistance and drug-induced nephrotoxicity are two key factors that limit the use of oncology drugs in clinical treatment. ${ }^{9}$ The internal environment of tumors is extremely complicated, and it also brings about great challenges to tumor treatment. Exploration of a tumor internal environment, especially the exploration of $\mathrm{O}_{2}{ }^{-}$, will provide great insights for tumor treatment and prognosis. Studies have shown that tumor cells produce more $\mathrm{O}_{2}{ }^{--}$than normal cells, which is related to the high metabolic activity of tumor cells. ${ }^{2}$ And a large amount of experimental evidence indicates that the effect of $\mathrm{O}_{2}{ }^{--}$on cell 
fate varies with cellular ROS levels, and the role of $\mathrm{O}_{2}{ }^{\bullet-}$ in regulating cancer progression appears to be paradoxical. ${ }^{6}$ On the one hand, mild $\mathrm{O}_{2}{ }^{\bullet-}$ outbreaks can promote the occurrence and progression of cancer by transforming normal cells by activating transcription factors or inhibiting tumor suppressor genes. ${ }^{9-11}$ Meanwhile increased $\mathrm{O}_{2}{ }^{--}$levels can activate early growth-related genes, transcription factors and protein kinase activity. ${ }^{12-14}$ On the other hand, an elevated level of $\mathrm{O}_{2}{ }^{\bullet-}$ can also stimulate pro-apoptotic signals, thereby inhibiting cancer progression and causing cancer cells to die. ${ }^{2}$ Redox metabolism that maintains $\mathrm{O}_{2}{ }^{\bullet-}$ homeostasis (the ratio between production and detoxification) is vital in the regulation of cell signaling and cell death. ${ }^{55,56}$ Therefore, it is necessary to detect $\mathrm{O}_{2}{ }^{\bullet-}$ during tumor treatment.

Improving tumor therapeutic effects and reducing the side effects caused by tumor treatment have always been two major challenges in tumor treatment. cis-Diaminodichloroplatinum(II) (DDP) is one of the most widely used chemotherapeutic agents. Despite its success in treating tumor, it has caused significant challenges for tumor treatment due to acquired or intrinsic drug resistance. ${ }^{15}$ Besides, the main complication of DDP treatment, nephrotoxicity, is the main factor of dose limitation. ${ }^{16}$ Thus, finding effective adjunctive therapeutics that can improve tumor treatment and relieve nephrotoxicity may be a better way forward for tumor therapy. Curcumin (cum) is considered to be an effective anti-inflammatory and antioxidant compound, and it has a sensitization effect on tumor treatment. ${ }^{16}$ But, the specific sensitization mechanism is still vague. In addition, the auxiliary treatment effect of vitamin $\mathrm{C}(\mathrm{Vc})$, vitamin $\mathrm{E}$ (Ve) and GSH is worth exploring. ${ }^{41-49}$ This study aimed to investigate the sensitizing effects of cum, Vc, Ve and GSH on DDP through $\mathrm{O}_{2}{ }^{\bullet-}$ detection.

For $\mathrm{O}_{2}{ }^{\bullet-}$ detection, the main methods involve electrodes, SOD activity assays, and electron paramagnetic resonance. ${ }^{17-20}$ However, these methods are unable to achieve in situ and real-time $\mathrm{O}_{2}{ }^{--}$imaging due to the intricate sample pretreatment as well as destruction of tissues and cells required. Thus, powerful tools for non-invasive visualization of $\mathrm{O}_{2}{ }^{\bullet-}$ detection in complex biological systems are required urgently. Fluorescence imaging technology with high spatial and temporal resolution can meet our requirements for non-invasive $\mathrm{O}_{2}{ }^{\bullet-}$ detection in complex organisms. Although many fluorescent probes for $\mathrm{O}_{2}{ }^{\bullet-}$ detection have been designed, most of them are one-photon fluorescent probes. ${ }^{21-24}$ Two-photon fluorescent probes using a longer excitation wavelength in the near infrared region (NIR) can achieve deeper tissue imaging depth and higher spatiotemporal resolution. And most existing two-photon fluorescent probes for $\mathrm{O}_{2}{ }^{--}$detection are off-on type probes that have a short fluorescence emission wavelength and are susceptible to autofluorescence and environmental factors. ${ }^{25-28}$ Until now, a fluorescent probe for $\mathrm{O}_{2}{ }^{\bullet-}$ detection during tumor treatment has not been reported. We suppose that two-photon ratiometric fluorescent probes with longer fluorescence emission wavelength have more advantages for $\mathrm{O}_{2}{ }^{\bullet-}$ detection.

Here, we developed a ratiometric fluorescent probe, TP-Tfs, for $\mathrm{O}_{2}{ }^{\bullet-}$ detection in living cells and in vivo during the process of tumor treatment for the first time. The probe consisted of a two-photon fluorophore, TP-OH, and a classical response unit, triflate, for $\mathrm{O}_{2}{ }^{\bullet-}$ imaging. ${ }^{22}$ TP-Tfs with high selectivity and sensitivity can achieve $\mathrm{O}_{2}{ }^{--}$detection rapidly in 4 min without disturbance from other interfering species. Using TP-Tfs, we can track the $\mathrm{O}_{2}{ }^{\bullet-}$ concentration fluctuation effectively in living cells and in vivo. We also explored the concentration fluctuation of $\mathrm{O}_{2}{ }^{\bullet-}$ during tumor treatment with DDP and an auxiliary therapeutic agent. We investigated the relationship between $\mathrm{O}_{2}{ }^{\bullet-}$ concentration and the tumor treatment effect in an A549 xenograft nude mouse.

\section{Experimental}

\subsection{Synthesis of the probe}

Probe TP-Tfs (compound 3) was synthesized with compound 2 $(0.0342 \mathrm{~g}, 0.1 \mathrm{mM})$ and trifluoromethanesulfonic anhydride $(0.11 \mathrm{mmol})$ in a mixture of pyridine $(5 \mathrm{~mL})$ and $\mathrm{CH}_{2} \mathrm{Cl}_{2}$ $(5 \mathrm{~mL})$ under an Ar atmosphere. The mixture was stirred for $30 \mathrm{~min}$ at room temperature, and then the solvent was removed. The residue was purified by silica gel chromatography with $\mathrm{CH}_{2} \mathrm{Cl}_{2}$ /petroleum ether (v/v, $\left.3: 1\right)$ as eluent to afford an orange product $(0.035 \mathrm{~g}, 73.8 \%) .{ }^{1} \mathrm{H}$ NMR $\left(500 \mathrm{MHz}, \mathrm{CDCl}_{3}-\mathrm{D}_{1}\right)$ $\delta(\mathrm{ppm}): 8.69(2 \mathrm{H}, \mathrm{m}), 8.33(1 \mathrm{H}, \mathrm{d}), 8.23(1 \mathrm{H}, \mathrm{d}), 8.13(1 \mathrm{H}, \mathrm{d})$, $8.01(1 \mathrm{H}, \mathrm{s}), 7.89(1 \mathrm{H}, \mathrm{m}), 7.81(1 \mathrm{H}, \mathrm{m}), 7.68(2 \mathrm{H}, \mathrm{m}), 7.58(1 \mathrm{H}$, d), $4.80(1 \mathrm{H}, \mathrm{m}), 3.31(2 \mathrm{H}, \mathrm{s}), 1.91(6 \mathrm{H}, \mathrm{s}), 1.64(3 \mathrm{H}, \mathrm{t})$. LC-MS $\left(\mathrm{ESI}^{+}\right.$): $m / z \mathrm{C}_{25} \mathrm{H}_{23} \mathrm{~F}_{3} \mathrm{NO}_{3} \mathrm{~S}^{+}$calcd 474.51 , found $\left[\mathrm{M}^{+}\right] 474.21$.

\subsection{Confocal imaging}

Cells were plated on Petri-dishes $(\Phi=20 \mathrm{~mm})$ and adhered for $24 \mathrm{~h}$ before $\mathrm{O}_{2}{ }^{\bullet-}$ detection. The probe was added to the culture plates that were filled with $1 \mathrm{~mL}$ of fresh complete medium. One-photon fluorescent images were acquired on an Olympus Fluo View FV1000 confocal laser-scanning microscope (Japan). The two-photon fluorescent images were collected using a twophoton laser confocal microscope (Zeiss LSM 880). The excitation wavelength was described in the paper. The ratio signals were rebuilt from two fluorescence collection windows: channel 1: $\lambda_{\mathrm{em}}=460-560 \mathrm{~nm}\left(\lambda_{\mathrm{ex}}=440 \mathrm{~nm}\right)$, channel $2: \lambda_{\mathrm{em}}=560-660 \mathrm{~nm}$ $\left(\lambda_{\mathrm{ex}}=488 \mathrm{~nm}\right)$.

\subsection{Establishment of the DDP chemotherapy cell model using an adjuvant agent}

DDP Chemotherapy group: cells were incubated with $1 \mu \mathrm{g} \mathrm{mL}^{-1}$ DDP for $12 \mathrm{~h}$.

Cum supplementary DDP chemotherapy group: cells were incubated with $1 \mu \mathrm{g} \mathrm{mL} \mathrm{mL}^{-1} \mathrm{DDP}$ and different concentrations of cum $(0,0.1,1,10,100 \mu \mathrm{M})$ for $12 \mathrm{~h}$.

Vc supplementary DDP chemotherapy group: cells were incubated with $1 \mu \mathrm{g} \mathrm{mL} \mathrm{mL}^{-1} \mathrm{DDP}$ and different concentrations of $\mathrm{Vc}(0,0.1,1,10$, and $100 \mu \mathrm{M})$ for $12 \mathrm{~h}$.

Ve supplementary DDP chemotherapy group: cells were incubated with $1 \mu \mathrm{g} \mathrm{mL} \mathrm{m}^{-1} \mathrm{DDP}$ and different concentrations of $\mathrm{Ve}(0,0.1,1,10$, and $100 \mu \mathrm{M})$ for $12 \mathrm{~h}$.

GSH supplementary DDP chemotherapy group: cells were incubated with $1 \mu \mathrm{g} \mathrm{mL} \mathrm{mL}^{-1} \mathrm{DDP}$ and different concentrations of $\mathrm{GSH}(0,0.1,1,10$, and $100 \mu \mathrm{M})$ for $12 \mathrm{~h}$. 
All surgical procedures were conducted in conformity with the Care and Use of National Guidelines for the laboratory animals, and experimental protocols were approved by the Institutional Animal Care and Use Committee in Binzhou Medical University, Yantai, China. Approval number: no. BZ2014-102R.

\section{Results and discussion}

\subsection{Design and synthesis of TP-Tfs}

For $\mathrm{O}_{2}{ }^{\bullet-}$ detection, several major obstacles should be considered. $\mathrm{O}_{2}{ }^{\bullet-}$ shows a short half-life and low concentration in vivo that are not conducive to detection under physiological conditions. ${ }^{29}$ $\mathrm{O}_{2}{ }^{\bullet-}$ also has high reactivity and it can convert to other reactive oxygen species via cytochrome $c$ oxidase, SOD and so on. ${ }^{30,31} \mathrm{We}$ noticed that triflate can react with $\mathrm{O}_{2}{ }^{\bullet-}$ selectively and it is inert towards abundant intracellular reactive nucleophiles, such as amino acids and proteins that include reactive sulfur atoms under physiological conditions. ${ }^{22}$ Thus, we selected triflate as the response unit for $\mathrm{O}_{2}{ }^{\bullet-}$ detection due to its good selectivity, high sensitivity and rapid response. ${ }^{22}$ And we selected a two-photon fluorophore, TP-OH, as the chromophore because it can achieve higher time and spatial resolution as well as deeper tissue observation depth. As shown in Scheme 1, we integrated triflate and the fluorophore $\mathrm{TP}-\mathrm{OH}$ to obtain a desirable fluorescent probe, TP-Tfs, for $\mathrm{O}_{2}{ }^{\bullet-}$ detection. Triflate can efficaciously regulate the blue shift or red shift in emission caused by internal charge transfer (ICT). ${ }^{32}$ Thus, we can employ the ratiometric fluorescence signals to achieve $\mathrm{O}_{2}{ }^{\bullet-}$ detection. And the ratiometric fluorescence signals can eliminate interference caused by excitation and emission efficiencies as well as by variable factors from uneven loading or uneven distribution of the probe and environmental conditions. ${ }^{57}$ As shown in Scheme 1, we synthesized a ratiometric fluorescent probe with simple synthesis steps and high yields for $\mathrm{O}_{2}{ }^{\bullet-}$ detection sensitively and selectively. The nucleophilic attack by $\mathrm{O}_{2}{ }^{\bullet-}$ cleaved the ester bond and released the fluorophore TP-OH with a spectral red shift. The detailed synthetic steps of TP-Tfs have been described in the ESI $\dagger$ (Scheme S1).

\subsection{Spectral properties of probe TP-Tfs towards $\mathrm{O}_{2}{ }^{\bullet-}$}

The absorption and emission spectroscopic characteristics of TP-Tfs were investigated in buffer solution (10 mM HEPES buffer, $\mathrm{pH}$ 7.4). As shown in Fig. S1 (ESI $\dagger$ ), the free probe TP-Tfs displayed a maximum absorption peak centered at $400 \mathrm{~nm}$. After reacting with $\mathrm{O}_{2}{ }^{\bullet-}$, the maximum absorption peak changed to $450 \mathrm{~nm}$. The fluorescent spectra of TP-Tfs exhibited an obvious redshift from $520 \mathrm{~nm}$ to $580 \mathrm{~nm}$ in the maximum emission wavelength. The free probe TP-Tfs showed a maximum fluorescence emission peak centered at $520 \mathrm{~nm}\left(\Phi=4.04 \%, \delta_{\max }=73 \mathrm{GM}\right.$, Fig. 1a). After reacting with $\mathrm{O}_{2}{ }^{\bullet-}$, the fluorescence at $580 \mathrm{~nm}(\Phi=4.91 \%$, $\delta_{\max }=126 \mathrm{GM}$ ) increased gradually in a concentrationdependent manner, while the fluorescence at $520 \mathrm{~nm}$ decreased gradually (Fig. 1b).

And the ratio of signals $\left(F_{580 \mathrm{~nm}} / F_{520 \mathrm{~nm}}\right)$ of TP-Tfs increased with the increased $\mathrm{O}_{2}{ }^{--}$concentration (Fig. 1c). There existed a linear relationship between the logarithm of the ratio $\left(F_{580 \mathrm{~nm}} /\right.$ $\left.F_{520 n m}\right)$ and the $\mathrm{O}_{2}{ }^{\bullet-}$ concentrations and the linear regression equation was determined to be $\log ($ ratio $)=0.1057\left[\mathrm{O}_{2}{ }^{--}\right] \mu \mathrm{M}+$ 0.0065 with $r=0.9918$ (Fig. 1d). And the detection limit was $37 \mathrm{nM}$.

Given the rapid metabolism property of $\mathrm{O}_{2}{ }^{--}$in living cells, a fast reaction rate was needed. Then, we performed the reaction kinetics test to investigate whether TP-Tfs can track $\mathrm{O}_{2}{ }^{\bullet-}$ rapidly and selectively or not. As shown in Fig. 1e, TP-Tfs can respond to $\mathrm{O}_{2}{ }^{\bullet-}$ selectively and rapidly, and the ratio of fluorescence signals can rapidly reach saturation within $180 \mathrm{~s}$. The experimental results demonstrated that our TP-Tfs probe can track $\mathrm{O}_{2}{ }^{\bullet-}$ quickly, sensitively and selectively, and that it was a promising imaging tool for rapid intracellular $\mathrm{O}_{2}{ }^{\bullet-}$ detection. High selectivity is also required for $\mathrm{O}_{2}{ }^{\bullet-}$ detection in a complex intracellular environment. Next, we performed the selectivity test among a wide variety of interfering species (Fig. 1f). We found that the abundant intracellular ROS and RNS, including hydrogen peroxide $\left(\mathrm{H}_{2} \mathrm{O}_{2}\right)$, singlet oxygen $\left({ }^{1} \mathrm{O}_{2}\right)$, peroxyl radicals $\left(\mathrm{ROO}^{\bullet}\right)$, hypochlorite $\left(\mathrm{OCl}^{-}\right)$, hydroxyl radicals $\left({ }^{\bullet} \mathrm{OH}\right)$, cumene hydroperoxide $(\mathrm{CuOOH})$, methyl linoleate hydroperoxide (MeLOOH), tert-butylhydroperoxide $(t-\mathrm{BuOOH})$, nitric oxide (NO), nitroxyl ( $\mathrm{HNO})$, nitrite ions $\left(\mathrm{NO}^{2-}\right)$ and peroxynitrite $\left(\mathrm{ONOO}^{-}\right)$, cannot cause interferences towards $\mathrm{O}_{2}{ }^{\bullet-}$ detection under the simulated conditions. In addition, we examined the stability of the probe and the probe was stable enough under physiological conditions ( $\mathrm{pH}$ 7.4, Fig. S2, ESI $\dagger$ ). We compared TP-Tfs with some other two-photon fluorescent probes in terms of linear range, detection limit and the two-photon action cross-section, as shown in Table S1 (ESI $\dagger$ ), and the results demonstrated that TP-Tfs showed good spectral characteristics. In addition, the probe with simple synthesis steps showed longer fluorescence emission. Thus, our TP-Tfs probe is a good candidate for $\mathrm{O}_{2}{ }^{--}$detection in living cells and in vivo.

\section{3 $\mathrm{O}_{2}{ }^{\bullet-}$ detection in living cells}

Since the TP-Tfs probe showed excellent selectivity and sensitivity towards $\mathrm{O}_{2}{ }^{\bullet-}$, we further explored the potential application of TP-Tfs for the investigation of $\mathrm{O}_{2}{ }^{\bullet-}$ concentration fluctuations in living cells. Before cell imaging tests, we performed MTT assays to examine the cytotoxicity of TP-Tfs in A549 and SH-SY5Y cells. The high cell viability indicated that the TP-Tfs probe exhibited low cytotoxicity towards living cells (Fig. S3, ESI $\dagger$ ).

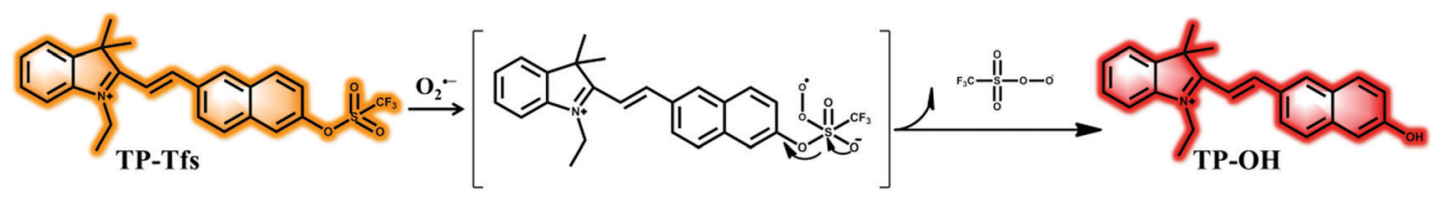

Scheme 1 The structure of TP-Tfs and its proposed reaction mechanism towards $\mathrm{O}_{2}{ }^{\bullet-}$. 

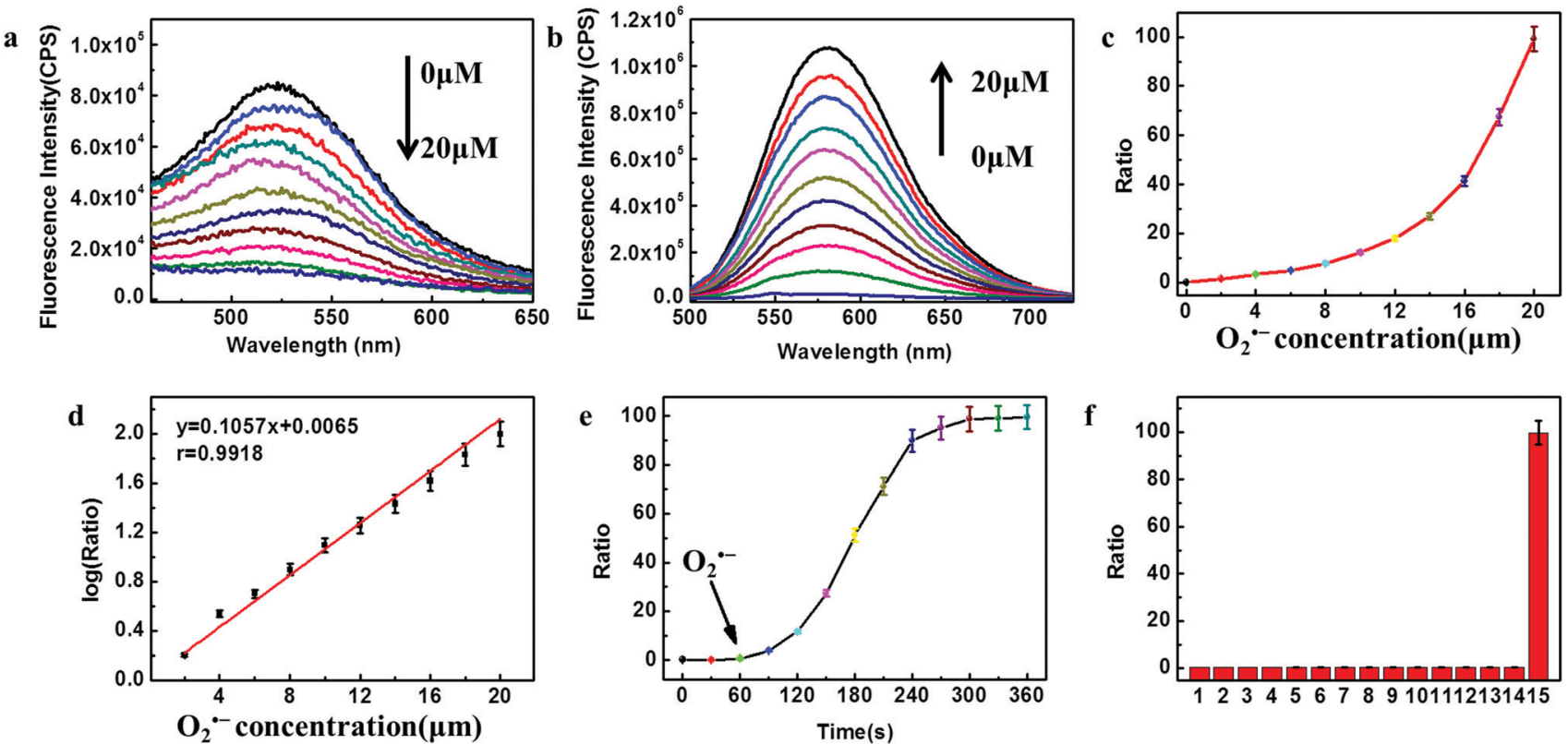

Fig. 1 Spectral properties and selectivity of TP-Tfs. Dose-dependent fluorescence spectra of TP-Tfs towards $\mathrm{O}_{2}{ }^{\bullet-}$. (a) $\lambda_{\text {ex }}=400 \mathrm{~nm}$. (b) $\lambda_{\text {ex }}=470 \mathrm{~nm}$. (c) Ratio of signals $\left(F_{580 \mathrm{~nm}} / F_{520 \mathrm{~nm}}\right)$ of TP-Tfs towards $\mathrm{O}_{2}{ }^{\bullet-}$. (d) Linear relationship between $\lg \left(F_{580 \mathrm{~nm}} / F_{520 \mathrm{~nm}}\right)$ and the concentrations of $\mathrm{O}_{2}{ }^{\bullet-}(0-10 \mu M)$. (e) Time-dependent fluorescence ratio $\left(F_{580 \mathrm{~nm}} / F_{520 \mathrm{~nm}}\right)$ of TP-Tfs towards $\mathrm{O}_{2}{ }^{--}$. (f) Fluorescence ratio $\left(F_{580 \mathrm{~nm}} / F_{520 \mathrm{~nm}}\right)$ response of TP-Tfs towards various interference species. 1, black; 2, $200 \mu \mathrm{M} \mathrm{NO}_{2}{ }^{-} ; 3,200 \mu \mathrm{M} \bullet \mathrm{OH}^{\prime}$ 4, $200 \mu \mathrm{M} \mathrm{ONOO}^{-} ; 5,200 \mu \mathrm{M}^{1} \mathrm{O}_{2} ; 6,200 \mu \mathrm{M} \mathrm{HNO} ; 7,200 \mu \mathrm{M} \mathrm{OCl} ; 8,200 \mu \mathrm{M} \mathrm{ROO}$; 9 , $200 \mu \mathrm{M} \mathrm{t-BuOOH} ; 10,200 \mu \mathrm{M} \mathrm{NO} ; 11,200 \mu \mathrm{M} \mathrm{CuOOH} ; 12,200 \mu \mathrm{M} \mathrm{H}_{2} \mathrm{O}_{2} ; 13,200 \mu \mathrm{M} \mathrm{MeLOOH} ; 14,200 \mu \mathrm{M} \mathrm{S}_{2} \mathrm{O}_{3}^{2-} ; 15,20 \mu \mathrm{M} \mathrm{O} 2^{\bullet-}$

Then, we selected A549 and SH-SY5Y cell lines as cell models to investigate the endogenous $\mathrm{O}_{2}{ }^{\bullet-}$ concentration fluctuations using different stimuli. The cell imaging tests were performed using a laser scanning confocal microscope and the fluorescence signals were collected from two channels: channel 1 (Ch 1) $\lambda_{\mathrm{ex}}=440 \mathrm{~nm}$ and $\lambda_{\mathrm{em}}=460-560 \mathrm{~nm}$; channel 2 (Ch 2) $\lambda_{\mathrm{ex}}=488 \mathrm{~nm}$ and $\lambda_{\mathrm{em}}=$ $560-660 \mathrm{~nm}$. And the pseudo-color ratio signals were reconstructed using ch 1 and ch 2 (Fig. 2a). The cells in the control group were

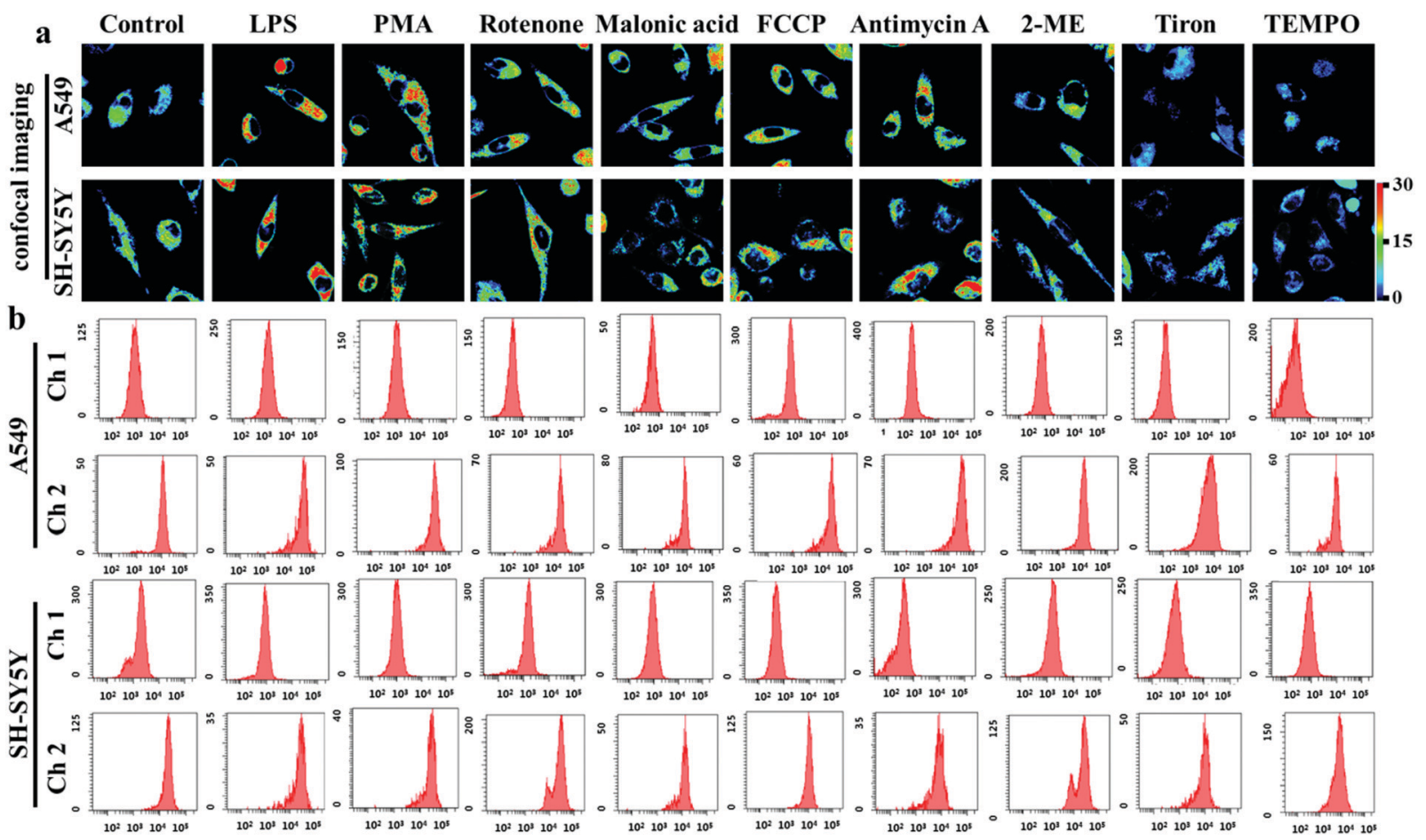

Fig. $2 \mathrm{O}_{2}{ }^{--}$imaging in $\mathrm{A} 549$ and SH-SY5Y cells. (a) Ratiometric imaging of $\mathrm{O}_{2}{ }^{--}$using a laser scanning confocal microscope. Ch 1: $\lambda_{\text {ex }}=440 \mathrm{~nm}$ and $\lambda_{\mathrm{em}}=460-560 \mathrm{~nm}$; Ch 2: $\lambda_{\mathrm{ex}}=488 \mathrm{~nm}$ and $\lambda_{\mathrm{em}}=560-660 \mathrm{~nm}$. (b) $\mathrm{O}_{2}{ }^{\bullet-}$ detection by flow cytometry analysis. 
incubated with TP-Tfs $(10 \mu \mathrm{M})$ for 5 min before imaging at $37{ }^{\circ} \mathrm{C}$, and we can capture bright fluorescence signals caused by $\mathrm{O}_{2}{ }^{--}$in normal cells.

The cells in other groups were subjected to the same operations as the control group before imaging. According to the literature, lipopolysaccharide (LPS) and phorbol-12-myristate-13-acetate (PMA) can induce ROS generation quickly in living cells. ${ }^{33} \mathrm{We}$ used LPS $\left(5 \mu \mathrm{g} \mathrm{mL}^{-1}\right)$ and PMA $\left(1 \mu \mathrm{g} \mathrm{mL} \mathrm{mL}^{-1}\right)$ to incubate cells for $1 \mathrm{~h}$, and we captured bright fluorescence signals compared to the control group. $\mathrm{O}_{2}{ }^{\bullet-}$ was mainly derived from the mitochondrial respiratory chain. There were four redox centers for $\mathrm{O}_{2}{ }^{\bullet-}$ generation in the mitochondria: NADH (ubiquinone oxidoreductase, complex I), succinate dehydrogenase (complex II), ubiquinol-cytochrome $c$ reductase (complex III), and cytochrome $c$ oxidase (complex IV), respectively. ${ }^{22}$ Then, we used four mitochondrial respiratory inhibitors to induce $\mathrm{O}_{2}{ }^{\bullet-}$ accumulation by blocking the redox centers on the respiratory chain, which were rotenone (a NADH inhibitor), malonic acid (a succinate dehydrogenase inhibitor), FCCP (succinate dehydrogenase) and antimycin A (a ubiquinol-cytochrome $c$ reductase inhibitor), respectively. ${ }^{22,34}$ The cells were incubated with rotenone $(20 \mu \mathrm{M})$, malonic acid $(500 \mu \mathrm{M})$, FCCP $(5 \mu \mathrm{M})$ and antimycin A $(20 \mu \mathrm{M})$ for $1 \mathrm{~h}$, and we observed stronger fluorescence signals. The four kinds of inhibitors were able to block the redox centers on the mitochondrial respiratory chain and cause $\mathrm{O}_{2}{ }^{\bullet-}$ accumulation. It was reported that 2-methoxyphylloate (2-ME) was an effective SOD inhibitor that can lead to $\mathrm{O}_{2}{ }^{\bullet-}$ accumulation. ${ }^{27}$ Next, we used 2-ME $\left(1 \mu \mathrm{g} \mathrm{mL}^{-1}\right)$ to incubate cells for $1 \mathrm{~h}$, and brighter fluorescence signals were obtained. 2,2,6,6-Tetramethylpiperidine$\mathrm{N}$-oxyl (TEMPO) and tiron are two mitochondria-targeting $\mathrm{O}_{2}{ }^{\bullet-}$ scavengers. ${ }^{22,35}$ Later, cells were incubated with tiron $(200 \mu \mathrm{M})$ for $10 \mathrm{~min}$ and TEMPO $(100 \mu \mathrm{M})$ for $30 \mathrm{~min}$, and decreased fluorescence signals can be observed. The corresponding average fluorescence intensities of Fig. 2a are shown in Fig. S4a (ESI $\dagger$ ). Flow cytometry analysis has been recognized as a technology that can quickly analyze millions of cells and produce convincing statistics. Thus, we performed flow cytometry analysis to confirm the above results, as shown in Fig. 2b. And the ratios (Ch 2/Ch 1 ) obtained from Fig. $2 \mathrm{~b}$ are shown in Fig. $\mathrm{S} 4 \mathrm{~b}$ (ESI $\dagger$ ). The results from the flow cytometry analysis (Fig. 2b) were consistent with that from the confocal microscope analysis, as shown in Fig. 2a. The above experimental results demonstrated that TP-Tfs possessed the ability to track endogenous $\mathrm{O}_{2}{ }^{--}$in living cells.

\subsection{Two-photon imaging in living cells}

Compared to one-photon fluorescent probes, two-photon fluorescent probes have many advantages such as higher spatiotemporal resolution, deeper imaging depth, less light loss and longer observation time. Then, we performed two-photon fluorescence imaging in living cells (Fig. 3). The cells in group a were incubated with $10 \mu \mathrm{M}$ TP-Tfs for $5 \mathrm{~min}$. One-photon microscopy (OPM) and two-photon microscopy (TPM) were performed for imaging. As shown in Fig. 3, OPM provided bright fluorescence imaging. Compared to OPM, TPM collected more specific fluorescence signals in cells at $4 \mu \mathrm{m}$. Then, the cells in group b were treated with LPS $\left(5 \mu \mathrm{g} \mathrm{mL}{ }^{-1}\right)$ for $1 \mathrm{~h}$ before the addition

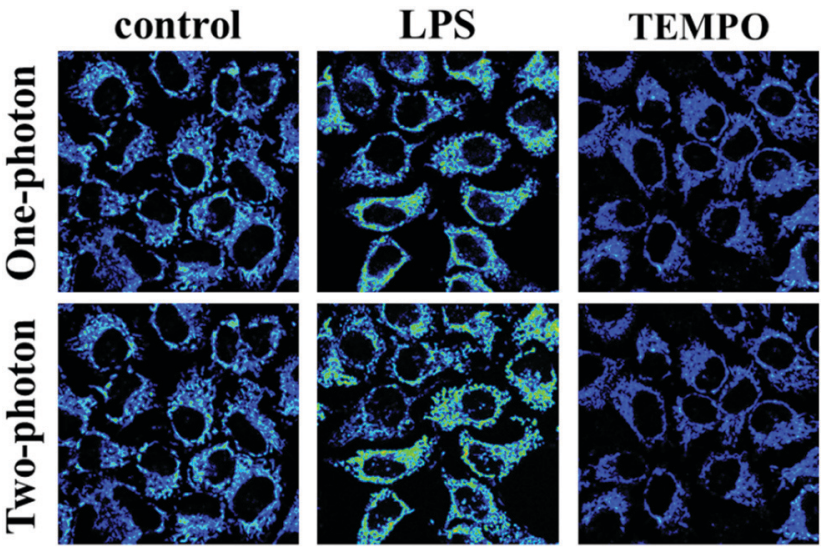

Fig. 3 Two-photon imaging in living cells.

of $10 \mu \mathrm{M}$ TP-Tfs. We found that the fluorescence signals were much brighter than those obtained from the control group, which confirmed that the concentration of $\mathrm{O}_{2}{ }^{\bullet-}$ was increased. After being treated with TEMPO, the fluorescence signals decreased. We can capture various physiological activities of cells by observing the collected fluorescent signals. And the corresponding average fluorescence intensities of Fig. 3 are shown in Fig. S5 (ESI $\dagger$ ). The above experiments indicated that TP-Tfs had the potential for deep imaging.

\section{5 $\mathrm{O}_{2}{ }^{\bullet-}$ detection in cell chemotherapy}

DDP is one of the most effective and the most widely applied drugs for tumor chemotherapy currently. ${ }^{36,37}$ However, the tumor resistance and nephrotoxicity caused by DDP are two challenges for tumor treatment. And the side effects of DDP in normal tissues and organs, especially nephrotoxicity, limit the application of DDP and related platinum drugs. The root cause of DDP cytotoxicity is that DDP interacts with DNA and forms covalent adducts with DNA bases. ${ }^{38,39}$ Kidney as the largest detoxification organ in vivo bears the role of drug detoxification. Thus, we tried our best to find auxiliary therapeutic agents to reduce nephrotoxicity caused by the chemotherapy drug DDP without reducing the efficacy of DDP. Curcumin (cum) extracted from turmeric has been considered as a dietary antioxidant that possesses therapeutic properties. ${ }^{40}$ According to reports, cum can not only sensitize the anti-tumor effect of chemotherapy drugs, but cum can also inhibit oxidative stress caused by chemotherapy drugs during tumor treatment in normal organs. ${ }^{41-43}$ Therefore, we want to explore the sensitizing effect of cum on DDP and the detoxification effect of cum on normal organs. It has been reported that vitamin $\mathrm{E}(\mathrm{Ve})$, vitamin $\mathrm{C}(\mathrm{Vc})$ and $\mathrm{GSH}$ can reduce oxidative stress during tumor treatment. ${ }^{44-50}$ Comparing the sensitizing effect of these reducing agents on tumor therapy and the detoxification effect on normal organs is vital for the accurate treatment of malignant tumors with minimal side effects. We selected the A549 cell line as the experimental model to identify the sensitizing effect of cum, Ve, Vc and GSH during tumor cell therapy with DDP through $\mathrm{O}_{2}{ }^{\bullet-}$ detection, as shown in Fig. 4.

The concentration fluctuations of $\mathrm{O}_{2}{ }^{\bullet-}$ were detected with probe TP-Tfs and the results are shown in Fig. 4 . The cells in the 


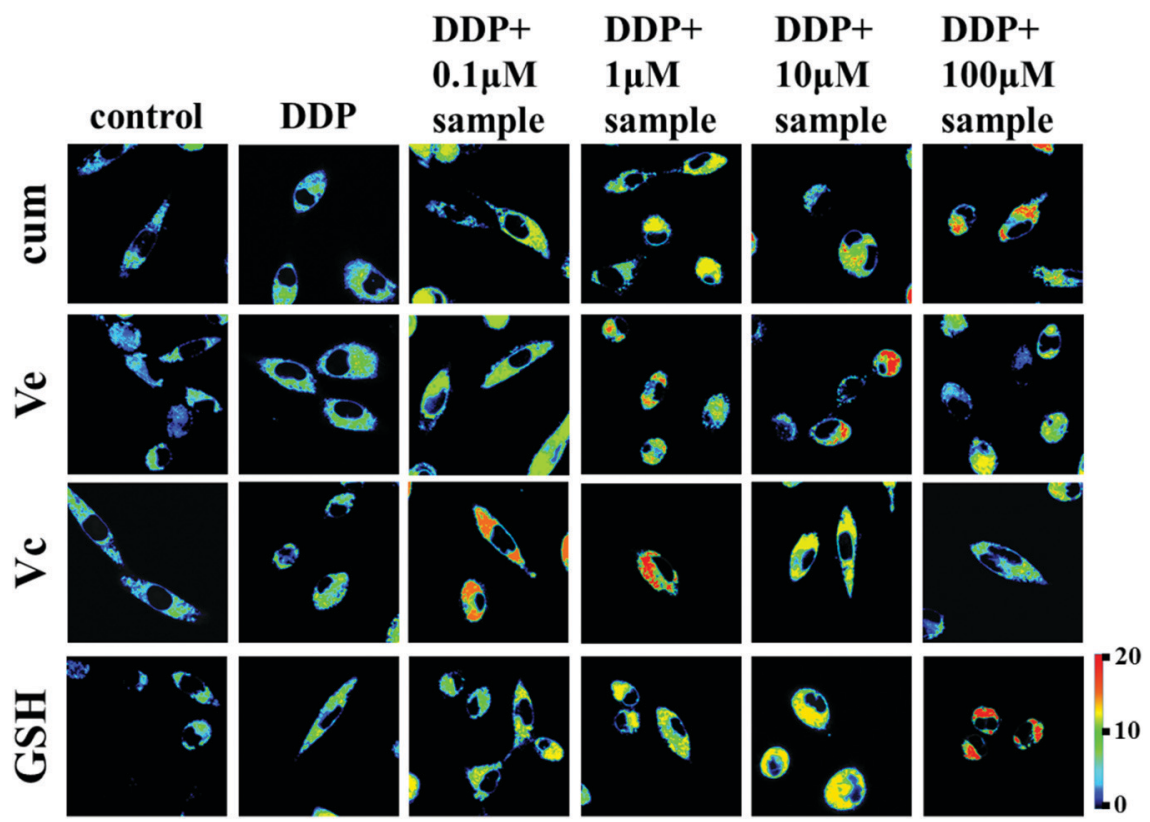

Fig. $4 \mathrm{O}_{2} \cdot{ }^{--}$detection by using a laser scanning confocal microscope. The images were reconstructed utilizing software Image-Pro Plus from two fluorescence collection windows, channel 1: $\lambda_{\mathrm{em}}=460-560 \mathrm{~nm}\left(\lambda_{\mathrm{ex}}=440 \mathrm{~nm}\right)$, channel $2: \lambda_{\mathrm{em}}=560-660 \mathrm{~nm}\left(\lambda_{\mathrm{ex}}=488 \mathrm{~nm}\right)$. The data are shown as mean $( \pm S D)$.

control group were incubated with TP-Tfs $(10 \mu \mathrm{M})$ for $5 \mathrm{~min}$ before imaging at $37{ }^{\circ} \mathrm{C}$, and the cells in the DDP group were treated with DDP $\left(1 \mu \mathrm{g} \mathrm{mL}{ }^{-1}\right)$ for $12 \mathrm{~h}$ before being taken as the control group. The cells in the other groups were taken as the DDP group, and then treated with different concentrations of the auxiliary therapeutic agent. We found that the concentration of $\mathrm{O}_{2}{ }^{\bullet-}$ was increased in a cum-dependent manner. Ve and Vc can induce the most severe oxidative stress when their concentrations reach $10 \mu \mathrm{M}$ and $1 \mu \mathrm{M}$, respectively. Too high Ve or Vc concentrations would lower $\mathrm{O}_{2}{ }^{\bullet-}$ concentration. In the GSH group, the concentration of $\mathrm{O}_{2}{ }^{\bullet-}$ was also increased in a GSH-dependent manner. The results were also confirmed by flow cytometry analysis and the results are shown in Fig. S8d (ESI $\dagger$ ). We further performed $\mathrm{O}_{2}{ }^{\bullet-}$ detection using a commercialized ROS probe, 2,7-dichlorodihydrofluorescein diacetate, and the results are shown in Fig. S7 (ESI $\dagger$ ). The analysis of average intensities for Fig. 4a and Fig. S7 is shown in Fig. S8c and e (ESI $\dagger$ ).

Then, the apoptotic levels of A549 cells in different therapeutic groups were calculated by an Annexin V-PE/7-AAD Apoptosis Detection Kit using flow cytometry, as shown in Fig. S8a (ESI $\dagger$ ). The cell apoptosis rates (including apoptosis and necrosis) in the cum group increased with the increased concentration of cum. Ve and Vc caused the most severe cell apoptosis when their concentration reached $10 \mu \mathrm{M}$ and $1 \mu \mathrm{M}$, respectively. We considered that the reason can be attributed to the high $\mathrm{O}_{2}{ }^{--}$ concentration. In the DDP + GSH group, we got the exact opposite result. The cell apoptosis rates were decreased with the increased GSH concentration. According to the research studies, DDP can form complexes with GSH and efflux out of the cells to reduce the mortality of tumor cells. ${ }^{53,54}$ And this process was one of the most extensive mechanisms of DDP resistance. ${ }^{53,54}$ We believed that GSH was committed to complexing with DDP instead of exerting its powerful reduction property to reduce oxidative stress. Calcium ions $\left(\mathrm{Ca}^{2+}\right)$ are one of the most vital second messengers involved in the regulation of physiologic processes in organisms. ${ }^{51}$ During the process of apoptosis, $\mathrm{Ca}^{2+}$ in the cytoplasm will increase abnormally. Next, we attempted to evaluate the concentration fluctuations of $\mathrm{Ca}^{2+}$ using Fluo 4-AM via flow cytometry, and the results are shown in Fig. S6 and S8f (ESI $\dagger$ ). We found that the trend of $\mathrm{Ca}^{2+}$ concentration was consistent with the trend of $\mathrm{O}_{2}{ }^{\bullet-}$ concentration, and we considered that the reason may be that oxidative stress caused mitochondrial damage and induced $\mathrm{Ca}^{2+}$ stored in the mitochondria to flow out to the cytoplasm. During the apoptotic stage, mitochondrial membrane potential $\left(\Delta \Psi_{\mathrm{m}}\right)$ is another important biomarker of cell damage, and $\mathrm{Ca}^{2+}$ outflow can cause $\Delta \Psi_{\mathrm{m}}$ collapse and directly induce apoptosis. ${ }^{52}$ We used the J-aggregate-forming lipophilic cation $5,5^{\prime}, 6,6^{\prime}$ tetrachloro-1,1' $1^{\prime}, 3,3^{\prime}$-tetraethylbenzimidazolyl-carbo-cyanine iodide (JC-1) to analyze $\Delta \Psi_{\mathrm{m}}$ via flow cytometry, and the results are shown in Fig. S8b (ESI $\dagger)$. We observed that $\Delta \Psi_{\mathrm{m}}$ decreased with the increased cum concentration. And the values of $\Delta \Psi_{\mathrm{m}}$ decreased dramatically when the concentrations of Ve and Vc increased up to $10 \mu \mathrm{M}$ and $1 \mu \mathrm{M}$, respectively. The values of $\Delta \Psi_{\mathrm{m}}$ in the GSH group increased with the increased GSH level. And the results obtained from JC-1 analysis were consistent with those obtained from cell apoptosis analysis. Comparing the experimental results, we found that cum had the strongest ability to sensitize the treatment effect of DDP by inducing $\mathrm{O}_{2}{ }^{--}$burst. Low concentrations of $\mathrm{Vc}$ and Ve can sensitize the tumor treatment effect of DDP, while high concentrations of Vc and Ve reduced the tumor treatment effect of DDP, which may be related to the finding that high concentrations of $\mathrm{Vc}$ and Ve reduced oxidative stress. As the most abundant biothiol with reducing characteristics in cells, GSH did not exert its powerful reducing property. GSH was committed 
to complexing with DDP to form a GSH-DDP compound and effused outside the cells to reduce cell death rate instead of resisting oxidative stress. According to these results, the sensitization effect of cum, Vc and Ve deserved further exploration in tumorbearing mice.

\section{6 $\mathrm{O}_{2}{ }^{--}$detection in tumor chemotherapy}

Encouraged by the results that cum, Vc and Ve may sensitize the tumor treatment effect of DDP, we further explored the sensitization effect of cum, Vc and Ve on DDP in tumor-bearing mice. Given the unsatisfactory results of GSH in cell experiments, we no longer performed experiments of the GSH group in tumor tests. The A549 xenografts were established in nude mice until the tumor volumes reached about $200 \mathrm{~mm}^{3}$. The mice were divided into five groups and we detected the concentration fluctuation of $\mathrm{O}_{2}{ }^{\bullet-}$ by a Bruker In vivo Imaging System with channel $1\left(\mathrm{Ch} 1, \lambda_{\mathrm{ex}}=430 \mathrm{~nm}, \lambda_{\mathrm{em}}=520 \mathrm{~nm}\right)$ and channel $2(\mathrm{Ch} 2$, $\left.\lambda_{\mathrm{ex}}=465 \mathrm{~nm}, \lambda_{\mathrm{em}}=580 \mathrm{~nm}\right) . \mathrm{O}_{2}{ }^{\bullet-}$ was detected by intratumorally injecting TP-Tfs ( $1 \mu \mathrm{M}, 50 \mu \mathrm{L}$ in 1:99 DMSO/saline $\mathrm{v} / \mathrm{v})$, and the fluorescence imaging lasted for $60 \mathrm{~min}$ without a fluorescence leak. The results from mice imaging are shown in Fig. 5a, and the corresponding fluorescence ratio analysis is shown in Fig. 5d. We captured bright fluorescence signals in the control group. The mice in the DDP group were given DDP $\left(0.5 \mathrm{mg} \mathrm{mL}^{-1} \times 0.5 \mathrm{~mL}\right)$ by intraperitoneal injection (i.p.) every other day. The $\mathrm{O}_{2}{ }^{\bullet-}$ concentration was increased greatly in the DDP group and we can observe higher ratios of signals compared to the control group. The mice in the Ve supplementary-DDP (DDP + Ve) group were taken as the DDP group and given Ve $\left(1 \mathrm{mg} \mathrm{g}^{-1}\right)$ twice a week. ${ }^{49,58}$ We found that the DDP + Ve group did not effectively reduce $\mathrm{O}_{2}{ }^{\bullet-}$ concentration. The mice in the Vc supplementary $(\mathrm{DDP}+\mathrm{Vc})$ group were treated as the DDP group and given Vc $\left(1 \mathrm{mg} \mathrm{g}^{-1}\right)$ twice a week. ${ }^{49,58}$ As shown in Fig. 5a, Vc can decrease $\mathrm{O}_{2}{ }^{\bullet-}$ concentration slightly. The mice in the cum supplementary (DDP + cum) group were treated as the DDP group and given cum $\left(50 \mathrm{mg} \mathrm{kg}^{-1}\right)$ three times a week. ${ }^{49,58}$ We can capture the brightest fluorescence signals in the DDP + cum group. Meanwhile, we recorded the tumor volume and tumor weight, and the results are shown in Fig. 5e and f. We also recorded the mice body weight, and the results are shown in Fig. 5g. The tumor volume and tumor weight in different groups can be ranked as control $>$ DDP $>$ $\mathrm{DDP}+\mathrm{Ve}>\mathrm{DDP}+\mathrm{Vc}>\mathrm{DDP}+$ cum. Then, we performed hematoxylin and eosin (H\&E) staining for more intuitive pathological observation of tumors (Fig. 5b). We can observe the tightly arranged and vigorously growing tumor cells in the control group. However, the arrangement of tumor cells in the treatment groups became loose. Tunel staining can label broken DNA to show apoptosis of tumor cells. We evaluated the apoptosis degree of tumor cells using Tunel staining, as shown in Fig. $5 \mathrm{c}$. We found that the apoptosis degree of tumor cells was more severe in the
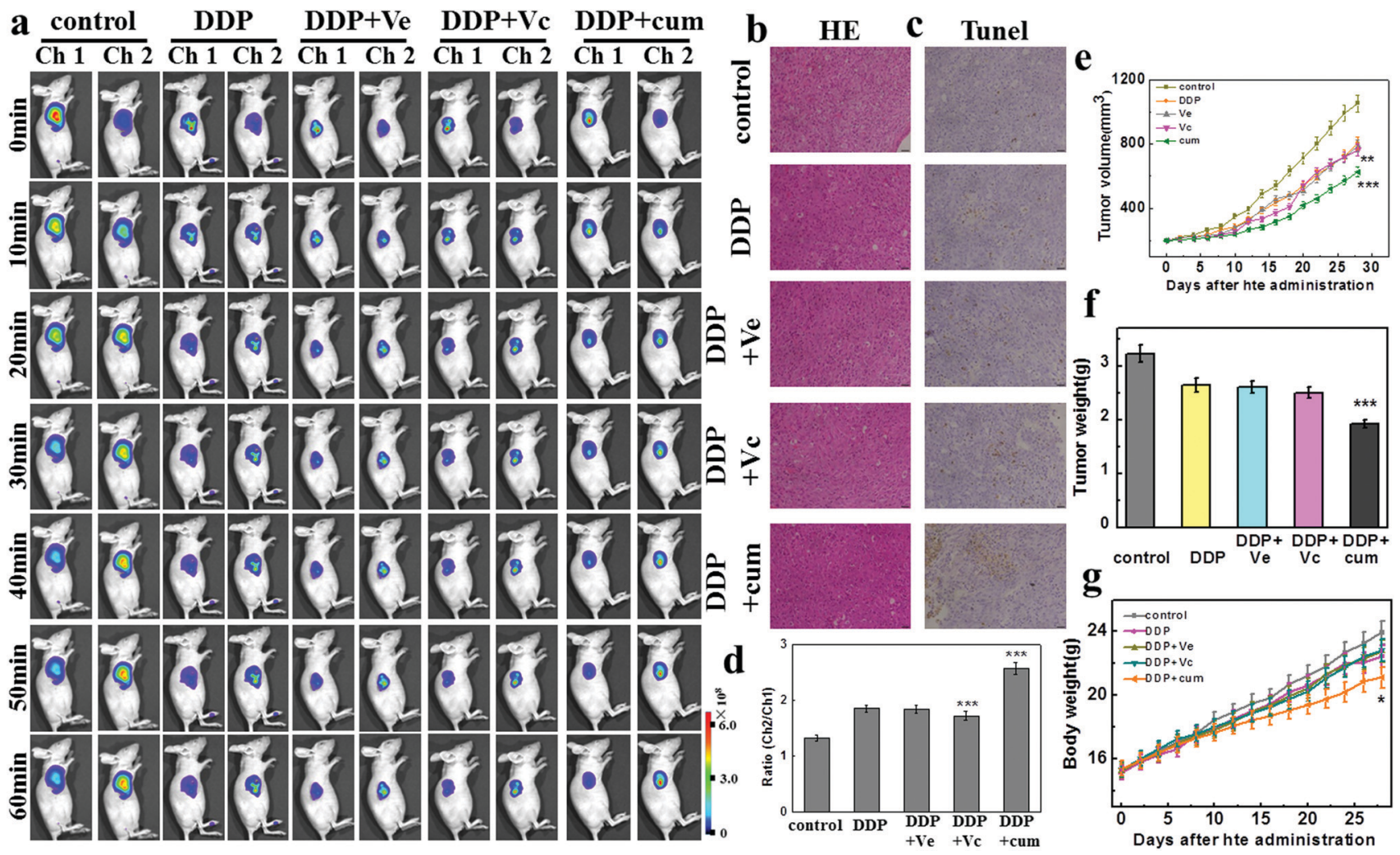

Fig. 5 (a) $\mathrm{O}_{2}{ }^{\bullet-}$ detection in A549 subcutaneous tumour xenograft mice. (b) HE staining. (c) Tunel staining. (d) The relative ratio fluorescence intensity analysis for (a). (e) Tumour sizes. The calculation of the volume followed the formula: volume $=$ length $\times$ width ${ }^{2} \times 0.5$. (f) Tumour mean weights. (g) Mice mean weights. The data are shown as mean ( \pm s.d.) $(n=7)$. The differences were determined with a one-way ANOVA. ${ }^{\star} P<0.05, * * P<0.01, * \star * P<$ 0.001 vs. DDP group. 
treatment group than the control group, especially in the DDP + cum group. The results demonstrated that the therapeutic effect of the DDP + cum group was the most effective. Cum can sensitize the tumor treatment effect of DDP by inducing $\mathrm{O}_{2}{ }^{\bullet-}$ burst to inhibit tumor growth effectively.

\section{Conclusions}

In summary, we have developed a ratiometric fluorescent probe, TP-Tfs, for $\mathrm{O}_{2}{ }^{\bullet-}$ detection. TP-Tfs exhibited good sensitivity and selectivity towards $\mathrm{O}_{2}{ }^{\bullet-}$ with a low detection limit. Using ratiometric fluorescence signals, we can track endogenous $\mathrm{O}_{2}{ }^{\bullet-}$ without interferences from other species and environmental factors. We applied TP-Tfs for $\mathrm{O}_{2}{ }^{\bullet-}$ detection in living cells and in vivo during the process of tumor treatment. And our experimental results demonstrate that cum can effectively sensitize the tumor therapeutic effect of DDP by inducing severe $\mathrm{O}_{2}{ }^{\bullet-}$ burst, and the sensitization effect of cum is the best among cum, Vc and Ve. Thus, cum may be an effective adjuvant that can sensitize tumor treatment. And we consider that TP-Tfs is a valuable candidate for drug screening and tumor treatment evaluation.

\section{Conflicts of interest}

There are no conflicts to declare.

\section{Acknowledgements}

We gratefully acknowledge the National Nature Science Foundation of China (No. 21976209, 21575159, and 21778026) and the Taishan Scholar Project Special Funding (No. ts20190962).

\section{References}

1 B. Halliwell, Free Radical Res., 1999, 31, 261.

2 C. Nicco, A. Laurent, C. Chereau, B. Weill and F. Batteux, Biomed. Pharmacother., 2005, 59, 169.

3 C. Richter, V. Gogvadze, R. Laffranchi, R. Schlapbach, M. Schweizer and M. Suter, Biochim. Biophys. Acta, 1995, 1271, 67.

4 Y. A. Suh, R. S. Arnold, B. Lassegue, J. Shi, X. Xu and D. Sorescu, Nature, 1999, 401, 79.

5 S. Corda, C. Laplace, E. Vicaut and J. Duranteau, Am. J. Respir. Cell Mol. Biol., 2001, 24, 762.

6 S. Pervaiz and M. V. Clement, Int. J. Biochem. Cell Biol., 2007, 39, 1297.

7 V. J. Thannickal and B. L. Fanburg, Am. J. Physiol.: Lung Cell. Mol. Physiol., 2000, 279, L1005.

8 J. F. Turrens, J. Physiol., 2003, 552, 335.

9 S. Xanthoudakis, G. Miao, F. Wang., Y. C. Pan and T. Curran, EMBO J., 1992, 11, 3323.

10 H. Kamata and H. Hirata, Cell. Signalling, 1999, 11, 1.

11 J. M. McCord, N. Engl. J. Med., 1985, 312, 159.

12 R. H. Burdon, Free Radical Biol. Med., 1995, 18, 775.
13 R. H. Burdon, Biochem. Soc. Trans., 1996, 24, 1028.

14 R. H. Burdon, V. Gill and C. Rice-Evans, Free Radical Res. Commun., 1989, 7, 149.

15 M. Kartalou and J. M. Essigmann, Mutat. Res., Fundam. Mol. Mech. Mutagen., 2001, 478, 23.

16 A. Kuhad, S. Pilkhwal, S. Sharma, N. Tirkey and K. Chopra, J. Agric. Food Chem., 2007, 55, 10150.

17 R. H. Fabian, D. S. DeWitt and T. A. Kent, J. Cereb. Blood Flow Metab., 1995, 15, 242.

18 G. M. Rosen and B. A. Freeman, Proc. Natl. Acad. Sci. U. S. A., 1984, 81, 7269.

19 W. M. Armstead, Brain Res., 2001, 910, 19.

20 Y. Saito, Y. Yoshida, T. Akazawa, K. Takahashi and E. Niki, J. Biol. Chem., 2003, 278, 39428.

21 K. M. Robinson, M. S. Janes, M. Pehar, J. S. Monette, M. F. Ross, T. M. Hagen and J. S. Beckman, Proc. Natl. Acad. Sci. U. S. A., 2006, 103, 15038.

22 (a) J. J. Hu, N. K. Wong, S. Ye, X. Chen, M. Y. Lu, A. Q. Zhao and D. Yang, J. Am. Chem. Soc., 2015, 137, 6837; (b) X. Han, R. Wang, X. Song, F. Yu, C. Lv and L. Chen, Biomaterials, 2018, 156, 134.

23 Y. Wang, M. Gao, Q. Chen, F. Yu, G. Jiang and L. Chen, Anal. Chem., 2018, 90, 9769.

24 Y. Wang, M. Gao, C. Liao, F. Yu and L. Chen, Sens. Actuators, $B, 2019$, 301, 127038.

25 W. Zhang, J. Zhang, P. Li, J. Liu, D. Su and B. Tang, Chem. Sci., 2019, 10, 879.

26 W. Zhang, D. Su, P. Li, J. Zhang, J. Liu, H. Wang and B. Tang, Chem. Commun., 2019, 55, 10740.

27 R. Q. Li, Z. Q. Mao, L. Rong, N. Wu, Q. Lei, J. Y. Zhu and Z. H. Liu, Biosens. Bioelectron., 2017, 87, 73.

28 Y. Xuan and J. Qu, RSC Adv., 2018, 8, 4125.

29 D. Han, F. Antunes, R. Canali, D. Rettori and E. Cadenas, J. Biol. Chem., 2003, 278, 5557.

30 D. Ganini, J. H. Santos, M. G. Bonini and R. P. Mason, Cell. Chem. Boil., 2018, 25, 413.

31 S. Zemanovic, M. V. Ivanov, L. V. Ivanova, A. Bhatnagar, T. Michalkiewicz, R. J. Teng and A. J. Afolayan, Cell Rep., 2018, 25, 2605.

32 M. Gao, F. Yu, H. Chen and L. Chen, Anal. Chem., 2015, 87, 3631 .

33 J. Wang, L. Liu, W. Xu, Z. Yang, Y. Yan, X. Xie and J. Hua, Anal. Chem., 2019, 91, 5786.

34 M. Kruidering, B. Van de Water, E. de Heer, G. J. Mulder and J. F. Nagelkerke, J. Pharmacol. Exp. Ther., 1997, 280, 638.

35 A. Paky, J. R. Michael and T. M. Burke-Wolin, J. Appl. Physiol., 1993, 74, 2868.

36 N. Pabla and Z. Dong, Kidney Int., 2008, 73, 994.

37 H. H. Mansour, H. F. Hafez and N. M. Fahmy, J. Biochem. Mol. Biol., 2006, 39, 656.

38 S. Dasari and P. B. Tchounwou,, Eur. J. Pharmacol., 2014, 740, 364.

39 Y. I. Chirino and J. Pedraza-Chaverri, Exp. Toxicol. Pathol., 2009, 61, 223.

40 A. B. Kunnumakkara, S. Guha, S. Krishnan, P. Diagaradjane, J. Gelovani and B. B. Aggarwal, Cancer Res., 2007, 67, 3853. 
41 L. M. G. Antunes, J. D. A. C. Darin and P. B. Maria de Lourdes, Pharmacol. Res., 2001, 43, 145.

42 M. Li, Z. Zhang, D. L. Hill, H. Wang and R. Zhang, Cancer Res., 2007, 67, 1988.

43 E. M. Jung, J. H. Lim, T. J. Lee, J. W. Park, K. S. Choi and T. K. Kwon, Carcinogenesis, 2005, 26, 1905.

44 A. Pace, A. Savarese, M. Picardo, V. Maresca, U. Pacetti, G. Del Monte and L. Bove, J. Clin. Oncol., 2003, 21, 927.

45 A. Pace, D. Giannarelli, E. Galie, A. Savarese, S. Carpano, M. Della Giulia and B. Jandolo, Neurology, 2010, 74, 762.

46 D. Appenroth, S. Fröb, L. Kersten, F. K. Splinter and K. Winnefeld, Arch. Toxicol., 1997, 71, 677.

47 L. M. G. Antunes, J. D. A. C. Darin and M. D. L. P. Bianchi, Pharmacol. Res., 2000, 41, 405.

48 C. M. Kurbacher, U. Wagner, B. Kolster, P. E. Andreotti, D. Krebs and H. W. Bruckner, Cancer Lett., 1996, 103, 183.

49 M. F. Chen, C. M. Yang, C. M. Su and M. L. Hu, Nutr. Cancer, 2014, 66, 1085.

50 M. Satoh, Y. Aoki and C. Tohyama, Cancer Chemother. Pharmacol., 1997, 40, 358.
51 P. Nicotera, G. Bellomo and S. Orrenius, Annu. Rev. Pharmacol., 1992, 32, 449.

52 S. T. Smiley, M. Reers, C. Mottola-Hartshorn, M. Lin, A. Chen, T. W. Smith, G. D. Steele Jr and L. B. Chen, Proc. Natl. Acad. Sci. U. S. A., 1991, 88, 3671.

53 S. Goto, K. Yoshida, T. Morikawa, Y. Urata, K. Suzuki and T. Kondo, Cancer Res., 1995, 55, 4297.

54 A. De Luca, L. J. Parker, W. H. Ang, C. Rodolfo, V. Gabbarini, N. C. Hancock and M. W. Parker, Proc. Natl. Acad. Sci. U. S. A., 2019, 116, 13943.

55 X. Chen, X. Tian, I. Shin and J. Yoon, Chem. Soc. Rev., 2011, 40, 4783.

56 C. M. Park, L. Weerasinghe, J. J. Day, J. M. Fukuto and M. Xian, Mol. BioSyst., 2015, 11, 1775.

57 Y. Wang, L. Zhang, S. Zhang, Z. Liu and L. Chen, Anal. Chem., 2019, 91, 7812.

58 (a) M. F. Chen, C. M. Yang, C. M. Su and M. L. Hu, Nutr. Cancer, 2014, 66, 1085; (b) V. M. Duarte, E. Han, M. S. Veena, A. Salvado, J. D. Suh, L. J. Liang and M. B. Wang, Mol. Cancer Ther., 2010, 9, 2665. 